\title{
Pharmacokinetic Interactions of Antiepileptic Drugs
}

\author{
Penny S. Albright and J. Bruni
}

\begin{abstract}
The problem of antiepileptic drug interactions is significant in that many epileptic patients are treated with multiple drug therapy. Moreover, patients may also be receiving additional medication for other concurrent disorders. Most drug interactions are pharmacokinetic, involving changes in absorption, protein binding, metabolism, or excretion. As a result, plasma levels of the antiepileptic drug may decrease leading to exacerbation of seizures. Alternatively, plasma levels may rise resulting in toxic side effects. Similar changes may also occur with drugs given for other disorders. In this paper, possible mechanisms of drug interactions are discussed. This is followed by a description of clinically significant interactions involving phenytoin, carbamazepine, barbiturates, valproic acid, benzodiazepines, and succinimides. Potentially serious drug interactions may be minimized by using as few medications as possible and by regularly monitoring plasma levels of antiepileptic drugs.
\end{abstract}

RÉSUMÉ: Le problème des interactions entre les drogues anticonvulsivantes est important car beaucoup des patients épileptiques reçoivent le traitement des plusieurs médicaments. D’ailleurs quelques patients prennent aussi des drogues supplémentaires pour autres maladies. La plupart des interactions sont pharmacokinétiques, associées à des changements de l'absorption, de la fixation à des protéines, du métabolisme, ou de l'excrétion. En conséquence les niveaux plasmiques de la drogue antiépileptique peuvent diminuer et exacerber des convulsions. Au contraire, les teneurs plasmiques peuvent augmenter avec le résultat de la toxicité. Des changements semblables pourraient avoir lieu avec des drogues ordonnées pour autres maladies. Dans cet article, les mécanismes possibles des interactions des drogues se discutent. Cela se suit de la description des interactions importantes cliniques en ce qui concerne la phénytoïne, la carbazazépine, les barbiturates, l'acide valproique, les bendodiazépines, et les suximides. Les interactions entre les drogues les plus potentiellement graves peuvent être minimisées en employant le plus petit nombre des médicaments possible et en surveillant périodiquement les tenuers plasmiques des drogues anticonvulsivantes.

Can. J. Neurol. Sci. 1984; 11:247-251

Drug interactions are an important consideration in the treatment of epilepsy. Most epileptic patients are treated with multiple drug therapy and, furthermore, many patients receive additional medications for concurrent illnesses. Although there is a trend towards monotherapy, epileptic patients often are exposed to polypharmacy and, consequently, drug interactions are a frequent occurrence in this population.

The present discussion focuses on the problem of antiepileptic drug interactions. Possible mechanisms are discussed followed by a description of those interactions which are of clinical importance. Interactions leading to elevated plasma levels are dealt with separately from those resulting in lower levels of antiepileptic drugs.

\section{Mechanisms of Drug InTERaCtions}

Both pharmacokinetic and pharmacodynamic mechanisms may be responsible for drug interactions. Pharmacodynamic interactions involve a change in the response of the target organ leading to antagonism, synergism, or potentiation of drug effects. Pharmacokinetic interactions, on the other hand, involve changes in drug delivery to the site of action. Most drug interactions involve pharmacokinetic changes. Thus, although pharmacodynamic interactions will be considered, this paper concentrates primarily on the mechanisms underlying pharmacokinetic interactions. The major factors involved in pharmacokinetic drug interactions are changes in absorption, metabolism, protein binding, and excretion. Table 1 summarizes these mechanisms of drug interactions.

\section{Interactions in the Gastrointestinal Tract}

Drugs can interact in the gastrointestinal tract to affect the rate or the extent of absorption. Since a change in absorption rate does not alter drug bioavailability, this factor is not of great relevance in the present discussion. However, increases or decreases in the extent of absorption can have important consequences. Factors which may alter the absorption process include: 1) changes in gastric $\mathrm{pH}$ which may affect tablet 
Table 1: Mechanisms of Pharmacokinetic Drug Interactions

1. Absorption

2. Protein Binding

3. Biotransformation

4. Excretion

dissolution; 2) chelation of drugs with metals or ions; and 3) stimulation or inhibition of gut enzymes. Changes in gastric motility may affect the rate of absorption but rarely alter the total amount of drug absorbed.

\section{Changes in Drug Metabolism}

Most antiepileptic drugs undergo metabolism by enzymes located in the smooth endoplasmic reticulum of the liver. Metabolism consists of two phases which may occur separately or in series: phase 1 which involves oxidation-reduction reactions, and phase 2 which involves conjugation with glucuronide, sulphate, or acetic acid. This process converts the drugs into more polar, water-soluble metabolites which can then be easily eliminated by the kidney. The activity of hepatic drug metabolizing enzymes can be greatly affected by the administration of various therapeutic agents. Certain agents are known to increase or induce hepatic enzymes leading to increased biotransformation of various compounds. This effect would result in reduced efficacy except when active metabolites are produced. In that case, therapeutic effects may be enhanced depending on the relative activity of the metabolite and the parent drug.

Inhibition of drug metabolism is also known to occur when two compounds are co-administered. Inhibition may be competitive in that both drugs are competing for the same enzyme or it may be non-competitive in that one drug inactivates the enzyme responsible for metabolism of the other. Non-competitive inhibition is likely to cause a continuous increase in plasma levels of the primary drug whereas competitive inhibition would lead to stabilization at a new plateau (Kutt, 1975).

\section{Changes in Protein Binding}

If two highly protein-bound drugs are administered together, one drug may be displaced with a resultant increase in free levels. The ultimate effect of this change depends on whether elimination of the drug in question is restrictive or non-restrictive.

Restrictive elimination means that the extraction of the drug is less than the free fraction in blood. Displacement of such a drug from protein binding sites would initially lead to an elevation in free fraction with an increase in therapeutic effect or toxicity. However, this effect would be transient, since the increased free levels would lead to increased elimination. Free drug concentration would then return to the previous level although total plasma levels would be considerably reduced (Shand et al., 1975; Gillette, 1973). This change in total levels may be misleading to the clinician, and free drug levels should be determined.

Drugs subject to non-restrictive elimination are highly extracted by the liver and the extraction ratio therefore exceeds the free fraction of the drug. Displacement of such drugs from protein binding sites results in an increase in volume of distribution and half-life (Shand et al., 1975). Free drug levels may rise since little increase in elimination would occur. In fact, however, protein binding interactions involving these drugs are seldom clinically important (Shand et al., 1975).

\section{Changes in Renal Excretion}

Drug interactions at the renal level typically involve changes in tubular secretion or reabsorption. Theoretically they also may involve changes in glomerular filtration and renal blood flow although these are rarely observed (Shand et al., 1975). Changes in tubular reabsorption can be caused by alterations in urinary $\mathrm{pH}$. For example, weak acids are eliminated more rapidly in alkaline urine whereas weak bases are excreted more effectively when the $\mathrm{pH}$ is low. Tubular secretion can be affected when two drugs are given which compete for acidic or basic compounds. Coadministration of two acidic drugs may retard tubular secretion of one of them. Secreted basic drugs may interact in a similar manner.

\section{ANTIEPILEPTIC DRUG INTERACTIONS}

\section{Phenytoin}

Drugs elevating plasma phenytoin levels. A number of drugs are reported to cause increases in plasma phenytoin levels (Table 2). With respect to other antiepileptic drugs, only a few are thought to raise phenytoin concentrations. For example, the metabolite of methsuximide competes with phenytoin for metabolic enzymes and, when both are administered, phenytoin toxicity may occur (Rambeck, 1979). Competitive inhibition between phenytoin and phenobarbital also has been reported (Patsalos and Lascelles, 1977). However, the ability of phenobarbital to induce the enzymes involved in phenytoin biotransformation can counteract this effect.

With respect to other types of medications, disulfiram (Olesen, 1967) and sulthiame (Houghton and Richens, 1974) both inhibit phenytoin metabolism leading to increases in plasma concentrations. Isoniazid, an antituberculosis agent, increases phenytoin levels in about $10 \%$ of epileptic patients (Kutt et al., 1966). Slow acetylators are more likely to exhibit this effect (Brennan et al., 1970). Although chloramphenicol can increase plasma phenytoin

Table 2: Drug Interactions Involving Phenytoin

Drugs Increasing Phenytoin Levels
Disulfiram
Sulthiame
Isoniazid
Chloramphenicol
Bishydroxycoumarin
Propoxyphene
Methsuximide
Drugs Decreasing Phenytoin Levels
Ethanol
Carbamazepine
Valproic Acid (transiently)
Antacids
Phenobarbital
Other Drugs Affected by Phenytoin
(Plasma Levels are decreased)
Oral Contraceptives
Bishydroxycoumarin
Dexamethasone
Metapyrone
Quinidine


levels (Koup et al., 1978), antimicrobial agents are rarely given for long enough periods to induce severe clinical complications. Bishydroxycoumarin (Hansen et al., 1966) and propoxyphene (Dam et al., 1980) also are reported to elevate phenytoin concentrations.

Drugs decreasing phenytoin levels. Phenytoin concentration in plasma is decreased by the drugs shown in Table 2 . The antiepileptic drugs, phenobarbital and carbamazepine, can induce phenytoin metabolism leading to reduced levels (Kutt, 1975). Valproic acid causes a transient reduction of total phenytoin levels in the majority of patients (Bruni et al., 1979). This interaction is caused by valproic acid displacing phenytoin from protein binding sites, leading to elevated free phenytoin levels. The increase in free concentration results in a compensatory increase in metabolism, and total phenytoin concentration declines. After a number of weeks, valproic acid inhibits phenytoin metabolism and phenytoin levels rise again. (Bruni et al., 1980a).

Of the non-antiepileptic drugs, chronic ethanol consumption can reduce phenytoin levels by inducing metabolic enzymes (Kater et al., 1969). However, drug metabolism may be inhibited during acute ethanol intake (Kutt, 1975). Antacids have been reported to reduce absorption of phenytoin from the G.I. tract (Gdrnett et al., 1979).

\section{Effects of phenytoin on other drugs}

Table 2 shows those drugs which are affected by co-administration of phenytoin. One of the most significant interactions is the increased metabolism of contraceptive steroids leading to contraceptive failure in women taking phenytoin (Hempel and Klinger, 1976). Other drugs which are reduced by phenytoin administration include bishydroxycoumarin(Hansen et al., 1971), dexamethasone (McLelland and Jack, 1978), metapyrone (Meikle et al., 1969) and quinidine (Data et al., 1976).

\section{Carbamazepine}

Drugs elevating carbamazepine levels. Administration of propoxyphene to patients taking carbamazepine produces increased plasma levels and signs of carbamazepine toxicity (Levy and Pitlick, 1982).

Drugs decreasing carbamazepine levels. With chronic use, carbamazepine induces its own metabolism (autoinduction) with a resultant decrease in half-life (Eichelbaum et al., 1976). Carbamazepine metabolism is also highly inducible by other antiepileptic agents. For example, carbamazepine levels are reduced by concomitant therapy with phenytoin, phenobarbital (Christiansen and Dám, 1973), and primidone (Schneider, 1975). This phenomenon does not necessarily reduce therapeutic efficacy since the concentration of carbamazepine epoxide, the active metabolite, is higher in these patients (Levy and Pitlick, 1982).

Effects of carbamazepine on other drugs. Carbamazepine's powerful enzyme-inducing properties can also affect the metabolism of other drugs. Carbamazepine has been shown to increase the clearance of ethosuximide (Warren et al., 1980), clonazepam (Lai et al., 1978), and valproic acid (Bowdle et al., 1979).

\section{Barbiturates (phenobarbital and primidone)}

Drugs elevating barbiturate levels. Table 3 summarizes drug interactions involving barbiturates. One of the most clinically significant interactions is observed when phenobarbital and valproic acid are co-administered. When valproic acid is initially

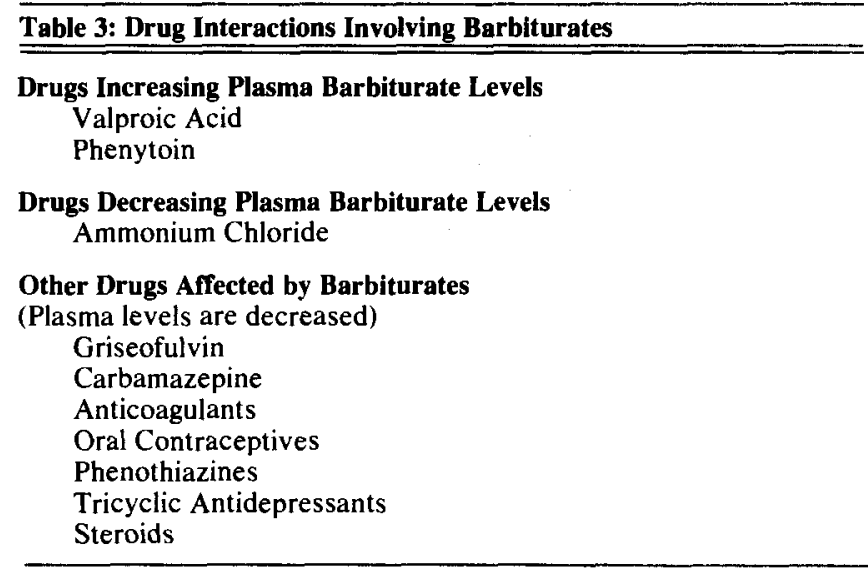

given to patients receiving phenobarbital, signs of somnolence or even coma may appear within days or weeks. These symptoms are accompanied by an increase in plasma phenobarbital levels (Bruni et al., 1980b). The mechanism of this effect is thought to involve an inhibition of phenobarbital metabolism as indicated by a reduction in the excretion of metabolite (Bruni et al., 1980b; Kapetanovic et al., 1981). However, since a large proportion of phenobarbital is excreted unchanged, additional factors are thought to contribute to phenobarbital accumulation (Kutt and Paris-Kutt, 1982).

It is of interest that when primidone and valproic acid are combined phenobarbital levels do not increase as predictably (Flachs et al., 1977). It has been speculated that valproic acid also inhibits the conversion of primidone to phenobarbital (Bruni, 1981; Windorfer and Sauer, 1977).

Co-administration of phenytoin may also elevate phenobarbital levels, although this is an infrequent occurrence. A competition for metabolic enzymes is thought to be responsible for this effect (Kutt and Paris-Kutt, 1982). Phenytoin is also thought to promote the conversion of primidone to phenobarbital (Fincham et al., 1974) although the clinical expression of this effect is questionable. Phenobarbital and primidone should not be given together since primidone is metabolized in part to phenobarbital. Most other antiepileptic drugs do not alter plasma phenobarbital levels.

Drugs decreasing barbiturate levels. Ammonium chloride can accelerate the elimination of phenobarbital and reduce plasma levels. Alkalinization of the urine by this or other agents increases renal excretion of the drug (Kutt and Paris-Kutt, 1928).

Effects of barbiturates on other drugs. Phenobarbital decreases the absorption of phenytoin and griseofulvin. Because of its powerful enzyme-inducing properties, phenobarbital may decrease phenytoin levels in some patients. However, it also competes with phenytoin as a substrate for parahydroxylation and glucuronidation. The net effect of these opposing changes is little or no change in phenytoin levels (Kutt et al., 1969). Phenobarbital also may cause a reduction in carbamazepine levels although this effect also is variable (Dam et al., 1975).

With respect to the nonantiepileptic drugs, phenobarbital can reduce levels of bishydroxycoumarin and warfarin (McDonald and Robinson, 1968; Cucinell et al., 1965). Induction of metabolism and possibly decreased absorption can account for these findings. Careful monitoring of prothrombin times should avoid serious consequences of this interaction. Enzyme induction can also 
lead to decreased levels of chlorpromazine (Loga et al., 1975), desipramine (Kutt and Paris-Kutt, 1982), and oral contraceptives (Hempel and Klinger, 1976). The elimination of endogenous substances such as bilirubin (Thompson et al., 1969), cholesterol, bile salts, lipids (Linarelli et al., 1973), endogenous steroids (Burstein and Klaiber, 1965), and vitamin D (Hunter, 1976) is accelerated by phenobarbital administration.

\section{Valproic Acid}

Drugs elevating valproic acid levels. The only factor known to increase valproic acid levels is the discontinuation of enzymeinducing antiepileptic drugs.

Drugs decreasing valproic acid levels. Concurrent use of other antiepileptic drugs can induce metabolic enzymes and reduce valproic acid concentrations (Reunanen et al., 1980). Removal of concomitant therapy may then cause a rebound increase in valproic acid levels (Johannessen and Henrikson, 1980). Administration of salicylate displaces valproic acid from protein binding sites (Fleitman et al., 1980) and leads to increased clearance and lower plasma concentrations (Schobben et al., 1978, Viswanathan and Levy, 1981). Endogenous fatty acids can also elevate the free fraction of valproic acid (Zimmerman et al., 1981).

Effects of valproic acid on other drugs. The interactions between valproic acid and phenytoin, phenobarbital, and primidone have been described in previous sections. Valproic acid may also lead to increased levels of carbamazepine (Mattson et al., 1982), and ethosuximide (Mattson and Cramer, 1980). In addition, the combined use of valproic acid and clonazepam may produce signs of toxicity and even absence status (Jeavons and Clark, 1974). The mechanism of this effect is unknown. Table 4 summarizes the major interactions involving valproic acid.

\section{Benzodiazepines}

Drugs elevating benzodiazepine levels. The clearance of diazepam and its active metabolite, $\mathrm{N}$-desmethyldiazepam is reduced by disulfiram (MacLeod et al., 1978) and cimetidine (Klotz et al., 1979).

Drugs decreasing benzodiazepine levels. The addition of other antiepileptic drugs may lower levels of clonazepam presumably by the induction of metabolic enzymes. Specific effects have been noted for carbamazepine (Lai et al., 1978), phenobarbital (Nanda et al., 1977), and phenytoin (Sjö et al., 1975).

Effects of benzodiazepines on other drugs. Pharmacodynamic interactions can occur between benzodiazepines and ethanol,

\section{Table 4: Drug Interactions Involving Valproic Acid}

Drugs Increasing Plasma Valproic Acid Levels

Withdrawal of enzyme inducing antiepileptic drugs

Drugs Decreasing Plasma Valproic Acid Levels

Phenobarbital

Primidone

Salicylate

Other Drugs Affected by Valproic Acid

Levels Increased:

Carbamazepine

Ethosuximide

Clonazepam

Phenobarbital

Levels Decreased:

Phenytoin (transiently) barbiturates, antihistamines, phenothiazines, and tricyclic antidepressants. Other than these, the benzodiazepines do not produce prominent interactions with other drugs probably because they have little capacity to induce hepatic enzymes. Clonazepam has little effect on phenytoin and carbamazepine although diminished phenobarbital levels have been reported (Benetello et al., 1977).

\section{Succinimides}

Drugs elevating succinimide levels. No significant interactions seem to produce increased levels of the succinimides.

Drugsdecreasing succinimide levels. Reduced levels of ethosuximide after addition of carbamazepine are probably due to enzyme induction (Warren et al., 1980).

Effects of succinimides on other drugs. The simultaneous administration of methsuximide with phenobarbital or phenytoin results in increased levels of the latter drugs. This effect is presumed to result from competitive inhibition of metabolic enzymes (Rambeck, 1979). Some increases in plasma phenytoin concentration occur after the addition of ethosuximide (Lander et al., 1975).

\section{CONCLUSIONS}

Important drug interactions may occur when two or more antiepileptic drugs are administered concurrently or if an antiepileptic drug is given together with another medication. Most drug interactions involve pharmacokinetic rather than pharmacodynamic changes. Such interactions can pose clinically important problems for the patient. In some cases the therapeutic efficacy of the antiepileptic medication is reduced leading to increased seizure frequency or, on the other hand, plasma concentrations may increase leading to toxic side effects. Similar effects have been observed with medications given for other disorders. Many potentially serious interactions can be avoided by careful monitoring of plasma levels of antiepileptic drugs. Although total concentrations are sufficiently informative for most purposes, free levels should be assessed in some situations (i.e. phenytoin-valproate interaction). However, maintenance of the epileptic patient on a single antiepileptic drug is the most effective way to avoid unwanted drug interactions.

\section{REFERENCES}

Benelello P, Furlanut M, Testa G, Santi R (1977) Effect of benzodiazepines on serum levels of phenobarbital and diphenylhydantoin. Riv. Farmacol. 8: 109-112.

Bowdle TA, Levy RH, Cutler RE (1979) Effects of carbamazepine on valproic acid in normal man. Clin. Pharmacol. Ther., 26: 629-634.

Brennan RW, Dehejia H, Kutt H. Verebly K, McDowell F (1970) Diphenylhydantoin intoxication attendant to slow activation of isoniazid. Neurology: 20, 687.693.

Bruni J (1981) Valproic acid and plasma levels of primidone and derived phenobarbital. Can. J. Neurol. Sci., 8: 91-92.

Bruni J, Gallo JM, Lee CS, Perchalski RJ, Wilder BJ (1980a) Interactions of valproic acid with phenytoin. Neurology, 30: 1233-1236.

Bruni J, Wilder BJ, Perchalski RJ, Hammond EJ, Viliarreal HJ (1980b) Valproic acid and plasma levels of phenobarbital. Neurology, 30: 94-97.

Bruni J, Wilder BJ, Willmore LJ (1979) Valproic acid and plasma levels of phenytoin. Neurology, 29: 904-905.

Burstein S, Klaiber EL (1965) Phenobarbital-induced increase in 6-betahydroxycortisol excretion: clue to its significance in human urine. J. Clin. Endocrinol. Metab., 25: 293-296.

Christiansen J, Dam M (1973) Influence of phenobarbital and diphenylhydant oin on plasma carbamazepine levels in patients with epilepsy. Acta. Neurol. Scand. 49: 543-546. 
Cucinell SA, Conney AH, Sansur MS, Burns JJ (1965) Drug interactions in man. I. Lowering effect of phenobarbital on plasma levels of bishydroxycoumarin (Dicoumarol) and diphenylhydantoin (Dilantin). Clin. Pharmacol. Ther., 6: 420-429.

Dam M, Christensen JM, Brandt J, Hansen BS, Huidberg EF, Angelo H, Lous P (1976) Antiepileptic drugs: interactions with dextropropoxyphene. In: Antiepileptic Therapy: Advances in Drug Monitoring, edited by SI Johannessen, PL Morselli, CE Pippenger, A Richens, D Schmidt, H Meinardi. Raven Press: New York, 299-304.

Dam M, Jensen A, Christiansen J (1975) Plasma levels and effect of carbamazepine in grand mal and psychomotor epilepsy. Acta Neurol. Scand. (Supp.), 60: 33-38.

Data JL, Wilkinson GR, Nies AS (1976) Interaction of quinidine with anticonvulsant drugs. New Eng. J. Med. 294: 699-702.

Eichelbaum M, Ekbom K, Bertilsson L, Lung L, Palmer L, Sjövist F (1976) Plasma levels of carbamazepine and carbanazepine -10, I1-epoxide during treatment of epilepsy. Eur. J. Clin. Pharamacol., 9: 417-421.

Fincham RW, Schottelius DD, Sahs A (1974) The influence of diphenylhydantoin on primidone metabolism. Arch. Neurol., 30: 259-262.

Flachs H, Wurtz-Jorgensen A, Granı L, Wulff K (1977) Sodium di-npropylacetate - its interaction with other antiepileptic drugs. In: Antiepileptic Drug Monitoring, edited by C Gardner-Thorpe, D Janz, H Meinardi, CE Pippenger. Pitman Medical: Kent, 165-171.

Fleitman JS, Bruni J, Perrin JH, Wilder BJ (1980). Albumin binding interaction of sodium valproate. J. Clin. Pharamacol., 20: 514-517.

Garnett WR, Carter BL, Pellock JM (1979) Bioavailability of phenytoin administered with antacids. Ther. Drug Monit., 1: 435-436.

Gillette JR (1973) Overview of drug-protein binding. Ann. N.Y. Acad. Sci. 179: 43-66.

Hansen JM, Kristensen M, Skovsted L, Christensen LK (1966) Dicoumarol-induced diphenylhydantoin intoxication. Lancet, 2: 265-266.

Hansen JM, Siersbaek-Nielsen K, Kristensen M, Skovsted L, Christensen LK (1971) Effect of diphenylhydantoin on the metabolism of dicoumarol in man. Acta. Med. Scand., 189: 15-19.

Hempel E, Klinger W (1976) Drug stimulated biotransformation of hormonal steroid contraceptives: Clinical implications. Drugs, 12: 442-448.

Houghton GW, Richens A (1974) Inhibition of phenytoin metabolism by sulthiame in epileptic patients. Br. J. Clin. Pharmacol., 1: 59-66.

Hunter J (1976) Effects of enzyme induction on vitamin $D_{3}$ metabolism in man. In: Anticonvulsant Drugs and Enzyme Induction, edited by A Richens and FP Woodford. Elsevier: New York, 77-84

Jeavons PM. Clark JE (1974) Sodium valproate in treatment of epilepsy. Br. Med. J., 2: 584-586.

Johannessen SI, Henriksen O (1980) Pharmacokinetic observations of sodium valproate in healthy subjects and patients with epilepsy. In: Antiepileptic Therapy: Advances in Drug Monitoring, edited by SI Johannessen, PL Morselli, CE Pippenger, A Richens, D Schmidt and H Meinardi. Raven Press: New York, 131-137.

Kapetanovic IM, Kupferberg HJ, Porter RJ, Theodore W, Schulman E, Penry JK (1981) Mechanism of valproate-phenobarbital interaction in epileptic patients. Clin. Pharmacol. Ther., 29: 480-486.

Kater RMH, Roggin G, Tobon F, Zieve P, Iber FL (1969) Increased rate of clearance of drugs from the circulation of alcoholics. Am. J. Med. Sci, 258: 35-39.

Klotz U, Anttila V-J, Reimann I (1979) Cimetidine/diazepam interaction. Lancet: $2,699$.

Koup JR, Gibaldi M, McNamara P, Hilligoss DM, Colburn WA, Bruck $E$ (1978) Interaction of chloramphenicol with phenytoin and phenobarbital. Clin. Pharmacol. Ther., 24: 571-575.

Kutt H, Winters W, McDowell F(1966) Depression of parahydroxylation of diphenylhydantoin by antituberculosis chemotherapy. Neurology (Minneap.), 16: 594-602.

Kutt H (1975) Interactions of antiepileptic drugs. Epilepsia, 16: 393-402.

Kutt H, Fouts J (1971) Diphenylhydantoin metabolism by rat liver microsomes and some of the effects of drug or chemical pretreatment on diphenylhydantoin metabolism by rat liver microsomal preparations. J. Pharamacol. Exp. Ther., 176: 11-26.

Kutt H, Haynes J, Verebely K, McDowell F (1969) The effect of phenobarbital on plasma diphenylhydantoin level and metabolism in man and rat liver microsomes. Neurology, 19: 611-616.

Kutt H, Paris-Kutt H (1982) Phenobarbital: Interactions with other drugs. In: Antiepileptic Drugs (2nd ed.), edited by DM Woodbury,
JK Penry and JK Pippenger. Raven Press: New York, 329-340.

Lai AA, Levy RH, Cutler RE (1978) Time course of interaction between carbamazepine and clonazepam in normal man. Clin. Pharmacol. Ther., 24: 316-323.

Lander CM, Eadie MJ, Tyrer JH (1975) Interactions between anticonvulsants. Proc. Aust. Assoc. Neurol., 12: 111-116.

Levy RH, Pitlick WH (1982) Carbamazepine: Interactions with other drugs. In: Antiepileptic Drugs (2nd ed.), edited by DM Woodbury, JK Penry and CE Pippenger. Raven Press: New York, 497-505.

Linarelli LG, Hengstenberg FH, Drash A (1973) Effect of phenobarbital on hyperlipemia in patients with intrahepatic and extrahepatic cholestasis. J. Pediatr., 83: 291-293.

Loga S, Curry S, Lader M (1975) Interactions of orphenadrine and phenobarbitone with chlorpromazine: Plasma concentrations and effects in man. Br. J. Clin. Pharamcol., 2: 197-208.

MacDonald MG, Robinson DS (1968) Clinical observations of possible barbiturate interference with anticoagulation. J.A.M.A., 204: 97-100.

MacLeod SM, Sellers EM, Giles HG, Billings BJ, Martin PR, Greenblatt DJ, Marshman JA (1978) Interaction of disulfiram with benzodiazepines. Clin. Pharmacol. Ther., 24: 583-589.

McLelland J, Jack W (1978) Phenytoin-dexamethasone interaction: A clinical problem, Lancet, 1: 1096-1097.

Mattson RH, Cramer JA (1980) Valproic acid and ethosuxinide interaction. Ann. Neurol., 7: 583-584.

Mattson GF, Mattson RH, Cramer JA (1982) Interaction between valproic acid and carbamazepine: An in vitro study of protein binding. Ther. Drug Monit., 4: 181-184.

Meikle AW, Jubiz W, Matsakura S, West CD, Tyler FH (1969) Effect of diphenylhydantoin on the metabolism of metapyrone and release of ACTH in man. J. Clin. Endocrinol., 29: 1553-1558.

Nanda RN, Johnson RH, Keogh HJ, Lambie DG, Melville ID (1977) Treatment of epilepsy with clonazepam and its effect on other anticonvulsants. J. Neurol. Neurosurg. Psychiat., 40: 538-543.

Olesen OV (1967) The influence of disulfiram and calcium carbimide on the serum diphenylhydantoin. Arch. Neurol., 16: 642-644.

Patsalos PM, Lascelles PT (1977) In vitro hydroxylation of diphenylhydantoin and its inhibition by other commonly used anticonvulsant drugs. Biochem. Pharmacol., 26: 1929-1933.

Rambek B (1979) Pharmacological interactions of methsuxinide with phenobarbital and phenytoin in hospitalized epileptic patients. Epilepsia, 20: 147-156.

Reunanen MI, Luoma P, Myllyla VV, Hokkanen E (1980) Low serum valproic acid concentrations in epileptic patients on combination therapy. Curr. Ther. Res., 28: 455-462.

Schneider H (1975) Carbamazepine: The influence of other antiepileptic drugs on its serum level. In: Clinical Pharmacology of Anti-epileptic drugs, edited by H Schneider, D Janz, C Gardner-Thorpe, H Meinardi and AL Sherwin. Springer Verlag: Berlin, 189-196.

Schobben F, Vree TB, Van Der Kleijn E (1977) Pharmacokinetics, metabolism and distribution of 2-N-propyl pentanoate (sodium valproate) and the influence of salicylate comedication. In: Advances in Epileptology, edited by H Meinardi and AJ Rowan. Sivets and Zeitlinger: Amsterdam, 271-277.

Shand DG, Mitchell JR, Oates JA (1975) Pharmacokinetic Drug Interactions. In: Handbook of Experimental Pharmacology, Vol. 28, edited by JR Gillette and JR Mitchell. Springer-Verlag: New York, 272-314.

Sjo O, Hvidberg EF, Naestoft J, Lund M (1975) Pharmacokinetics and side effects of clonazepam and its 7-amino-metabolite in man. Eur. J. Clin. Pharmacol., 8: 249-254.

Thompson RHP, Eddleston ALWF, Williams R (1969) Low plasmabilirubin in epileptics on phenobarbitone. Lancet, 1: 21-22.

Viswanathan CT, Levy RH (1981) Plasma protein binding interactions between valproic acid and salicylic acid in rhesus monkey. J. Pharm. Sci., 70: 1279-1281.

Warren JW, Benmaman JD, Wannamaker BB, Levy RH (1980) Kinetics of a carbamazepine-ethosuximide interaction. Clin. Pharmacol. Ther., 28: 646-651.

Windorfer A Jr, Sauer W (1977) Drug interactions during anticonvulsant therapy in childhood: diphenylhydantoin, primidone, phenobarbitone, clonazepam, nitrazepam, carbamazepine, and dipropylacetate. Neuropediatric, 8: 29-41.

Zimmerman CL, Patel IH, Levy RH, Edwards D, Nelson SD, Hutchison $M$ (1981) Protein binding of valproic acid in the presence of elevated free fatty acids in patient and normal human serum. Epilepsia, 22: 11-17. 